\section{Increased waist circumference as an independent predictor of hypercholesterolemia in community-dwelling older people}

\author{
Claudineia Matos de Araujo, ${ }^{1-3}$ \\ Marcos Henrique Fernandes, ${ }^{1,2}$ \\ José Ailton Oliveira Carneiro, 1,2 \\ Raildo da Silva Coqueiro, ${ }^{2}$ \\ Rafael Pereira ${ }^{1-3}$
}

${ }^{1}$ Postgraduate Program in Nursing \&

Health; ${ }^{2}$ Center for Studies in Aging

Epidemiology (NEPE); ${ }^{3}$ Research Group

in Neuromuscular Physiology,

Department of Biological Sciences, State

University of Southwest Bahia (UESB),

Jequié, Brazil

\begin{abstract}
Hypercholesterolemia is a worldwide public health problem, contributing to cerebrovascular and ischemic heart diseases as one of the major cardiovascular risk factors, and associated with approximately 4.4 million deaths each year worldwide. This study aimed to evaluate the association and predictive value of increased waist circumference (WC) to identify hypercholesterolemia in community-dwelling elderly people. In a cross-sectional, home-based epidemiological survey, 296 community-dwelling old adults consented to capillary blood collection and anthropometric evaluation. Total cholesterol was quantified, and the population was stratified as normal or high $(\geq 200$ $\mathrm{mg} / \mathrm{dL}$ ). WC was used to stratify the population into normal or elevated values (men: $\geq 90 \mathrm{~cm}$; women: $\geq 80 \mathrm{~cm}$ ). The association was investigated using logistic regression. Increased WC was associated with a greater probability of hypercholesterolemia (OR=2.82, 95\%CI 1.68 to 4.74$)$. Thus, the widely used WC cutoff was demonstrated to be significantly associated with hypercholesterolemia in community-dwelling elderly people and could serve as a useful screening tool for hypercholesterolemia in older adults.
\end{abstract}

\section{Introduction}

Elevated total cholesterol (i.e., hypercholesterolemia) is a worldwide public health problem contributing to cerebrovascular and ischemic heart diseases. ${ }^{1}$ In Brazil, as well as in other developing countries, cardiovascular diseases account for one third of all deaths and are the main source of healthcare expenditure. The hypercholesterolemia is one of the major cardiovascular risk factors and estimatives have associated hypercholesterolemia with approximately 4.4 million deaths each year worldwide. ${ }^{2}$ Additionally, it is estimated that, in 2025, the number of deaths/year attributed to hypercholesterolemia will increase to 25 million. ${ }^{3}$

It is known that the aging enhances the probability to develop cardiovascular and metabolic complications, including hypercholesterolemia. ${ }^{4}$ Notwithstanding, the body composition changes associated to aging process lead to an increased fat deposition with consequent cardiovascular and metabolic disorders, including insulin resistance, hyperlipidemia, hypertension, coronary artery disease. ${ }^{5}$

In this context, Rezende et al. (2006) observed that, in adults and older people, the abdominal or central obesity is correlated with many cardiovascular risk factors, including the hypercholesterolemia. The excessive body fat may be identified by anthropometric measurements, including body mass index (BMI), an indicator of overall obesity, and waist circumference (WC), an indicator of central or visceral obesity. ${ }^{6-8}$

Anthropometric measurements are easy-to-apply and low-cost when compared to more precise methods for body composition assessing, allowing its use in population-based studies to assess changes in body composition, as well as in clinical situations where access to technology is limited, ${ }^{5}$ which is especially important to developing countries. Thus, they should be used in household surveys, epidemiological population-based studies, clinical practice and primary health care in many scenarios. ${ }^{9}$

Although LDL cholesterol, total cholesterol/HDL ratio, and specific apolipoproteins can be better cardiovascular risk indicators, the analysis of total cholesterol alone is suitable for population studies, since the analysis of serum lipoproteins and apolipoproteins are not available for all population in many countries. ${ }^{2}$ Thus, this study aimed to evaluate the association and predictor value of increased waist circumference to identify hypercholesterolemia in community-dwelling older people.

\section{Materials and Methods}

This is a descriptive study with crosssectional design, which analyzed data from a home-based epidemiological survey called "Nutritional status, risk behaviors and health conditions of older people from
Correspondence: Rafael Pereira, Department of Biological Sciences, State University of Southwest Bahia, Rua José Moreira Sobrinho $\mathrm{s} / \mathrm{n}$, Jequiezinho, Jequie 45210-506, BA, Brazil.

E-mail: rafaelpereira@uesb.edu.br

Key words: anthropometry; aging; cholesterol.

Acknowledgements: the authors thank the Municipal Secretariat of Health of Lafaiete Coutinho-BA and the elderly who participated in the study.

Contributions: CMA, MHF, RSC, JAOC, data collecting and analyzing; CMA, RSC, JAOC, manuscript writing; MHF, funds collection; RP, MHF guiding overall work of the research.

Conflict of interest: the authors declare no potential conflict of interest.

Funding: this work was supported by the State University of Southwest Bahia (UESB) (Grant numbers UESB 117/2009 and 011/2010) and Foundation for Research Support of the State of Bahia (FAPESB) (Grant number PPP0070/2011).

Received for publication: 13 December 2016 Revision received: 23 June 2018,

Accepted for publication: 25 June 2018.

This work is licensed under a Creative Commons Attribution 4.0 License (by-nc 4.0)

(C) Copyright C.M. de Araujoet al., 2018

Licensee PAGEPress, Italy

Healthcare in Low-resource Settings 2018; 6:6468 doi:10.4081/hls.2018.6468

Lafaiete Coutinho, Bahia." The study was developed in Lafaiete Coutinho, Bahia, which had, registered in the Family Health Strategy (FHS), 3,901 inhabitants the urban area at the collection period. ${ }^{10}$

The study population consisted of all individuals aged $\geq 60$ years, of both sex, not institutionalized and residing in the urban area and registered in the FHS. From all residents in urban areas and aged $\geq 60$ years ( $\mathrm{n}$ $=355), 316(89.0 \%$ participated in the survey, it were registered 17 refusals $(4.8 \%)$ and $22(6.2 \%)$ subjects were not located after three home visits in different days, then, it were considered as losses.

The research procedures were approved by the local Ethics Committee ( ${ }^{\circ}$ 064/2010). Participation was voluntary, and individuals signed and informed consent, according to the ethical standards required by Resolution No $196 / 96$ of the National Health Council. 


\section{Data collection}

The data were collected in January 2011 by the interviewers with the support of community workers in each area of the FHS. Data were collected in two stages: the first stage consisted of home interviews with a previously validated questionnaire, ${ }^{11}$ which involved socio-demographic, lifestyle and cognitive evaluation. The second stage involved blood sampling, cardiorespiratory tests, anthropometric measurements and motor performance tests.

\section{Total cholesterol and hypercholes- terolemia (dependent variable)}

After 12 hours of fasting the total cholesterol (TC) was quantified from capillary blood samples with the Accutrend Plus ${ }^{\circledR}$ system (Roche Diagnostics, Germany), a previously validated analyzer. ${ }^{12}$ After 5 minutes of rest in a sitting position, capillary blood samples were collected through transcutaneous puncture on the medial side of the middle finger tip using a disposable hypodermic lancet. The study population was stratified into normal or Hypercholesterolemia according the recommended values ( $\mathrm{TC} \geq 200 \mathrm{mg} / \mathrm{dL}$ ) in the VI Brazilian Guidelines on Hypertension ${ }^{13}$ and $\mathrm{V}$ Brazilian Guidelines on Dyslipidemia and Prevention of Atherosclerosis. ${ }^{14}$

\section{Increased waist circumference (pre- dictor variable)}

The measurement of waist circumference (WC) was obtained with inelastic tape (graduated in centimeters), positioned over the umbilicus, with the patient standing. The International Diabetes Federation (IDF) in 2005 proposed a cutoff point for WC that differs between ethnic groups, being used in this study the cutoff $\geq 90 \mathrm{~cm}$ for men and $\geq 80 \mathrm{~cm}$ for women, as recommended by IDF for the ethnic group from Central and South Americans. ${ }^{15}$

\section{Statistical procedure}

Descriptive analysis was conducted with frequencies, means and standard deviations of the population characteristics. Initially, the chi-square test was applied to verify the association between waist circumference and the dependent variable hypercholesterolemia, which was confirmed ( $p<0.001)$. Thus, the data were submitted to logistic regression analysis to verify the association strength between variables. From the logistic regression parameters, the odd ratio was calculated with respective $95 \%$ confidence intervals (95\% CI). Data were analyzed in SPSS Statistics software for Windows (SPSS 21.0, 2012, Armonk, NY: IBM Corp.) and the significance level was $5 \%(\alpha=0.05)$.

\section{Results}

From the 316 older people included in the study, 296 (74.2 \pm 9.7 [60 to 105 ] years old) had total cholesterol and WC data collected. In this population, the prevalence of hypercholesterolemia was 51.4\% (152 subjects), which was higher in women (106 women, corresponding to $69.7 \%$ of all cases of hypercholesterolemia). Two hundred and seven $(69.9 \%)$ subjects presented WC above to the used cutoff values ( $\geq 90 \mathrm{~cm}$ for men and $\geq 80 \mathrm{~cm}$ for women), of whom 144 $(69.6 \%)$ were women.

The results from the logistic regression showed a strong association between WC (categorized) and hypercholesterolemia ( $\mathrm{p}$ $<0.001$ ). Table 1 shows the results of logistic regression, allowing to verify that a waist circumference measure above the established cutoff values ( $\geq 90 \mathrm{~cm}$ for men and $\geq 80 \mathrm{~cm}$ for women, respectively) impacts in greater chance of presenting hypercholesterolemia $(\mathrm{OR}=2.82,95 \% \mathrm{CI}$ 1.68 to 4.74$)$.

\section{Discussion}

This study aimed to investigate the association strength of WC and hypercholesterolemia in community-dwelling older people. The results showed that the increased WC was strongly associated to hypercholesterolemia in the studied population. The aging process is associated to significant changes fat, muscle and bone mass, with an increase of fat mass and decrease in muscle and bone mass. The accumulation of intra-abdominal fat (i.e., visceral fat) is a major risk factor for several diseases, and have attracted special attention when compared to other forms of body fat distribution, ${ }^{16}$ which is justified by the fact that visceral fat have different metabolic characteristics of subcutaneous fat that favor the installation of metabolic alterations that culminate in increased cardiovascular risk. ${ }^{17,18}$

The WC measurement does not allow inferring directly the amount of visceral fat, distinguishing from the subcutaneous fat in the abdominal section. However, Ross (2003), ${ }^{19}$ suggest that subcutaneous and visceral fat are highly correlated in the abdominal section. Additionally, Ribeiro Filho et al. (2006) ${ }^{18}$ and Rothberg et al. (2015), ${ }^{17}$ highlight that, among the available anthropometric methods to analyze the central distribution of body fat, the WC is the most widely used method for assessing visceral adiposity, because it is easy to collect and involves a single measure, being less subject to the measurement variability.

Zahorska-Markiewicz (2006) ${ }^{20}$ states that the WC is the best predictor to the development of cardiometabolic diseases. Rezende et al. (2006), ${ }^{6}$ studying a population with a wide age range (21-76 years) reported that the WC, as stratified here, is better associated to cardiometabolic risk factors, than the body mass index. Our results corroborate Zahorska-Markiewicz $(2006)^{20}$ and Rezende et al. (2006), ${ }^{6}$ and strengthen the understanding that the association between WC and hypercholesterolemia, an important cardiometabolic risk factor, is applies to the older people, since we found a greater association between hypercholesterolemia and increased $\mathrm{WC}(\mathrm{OR}=2.82,95 \%$ CI 1.68 to 4.74 ) in older people, independently of sex.

Nevertheless, Nagatsuyu et al. (2009) $)^{21}$ did not identify a significant association between waist circumference (measured at the umbilicus) and total cholesterol values. The form of analysis of the variable as continuous data, besides the fact that the cited study involved a smaller number of elderly people (only 98 older people), can justify the divergence from our results.

It is noteworthy that the accumulation of visceral fat also indicates a greater reserve of nutrients in the lipids form, so that the establishment of a cause-effect relationship between hypercholesterolemia and the visceral fat accumulation, as measured by WC, is complex. Our finds should encourage the use of anthropometric indicators of easy application and interpretation for clinical purposes and epidemiological research in order to prevent, maintain or improve monitoring of blood total cholesterol in the elderly of both sexes.

Table 1. Regression coefficient, Odds Ratio (OR) with its 95\% confidence interval (CI) obtained in the logistic regression. Lafaiete Coutinho, Bahia, Brazil, in 2011.

\begin{tabular}{lcccc} 
Variable & RC & Standard Error of RC & OR & $95 \%$ CI of OR \\
Waist Circumference & 1.038 & 0.265 & 2.82 & $1.68-4.74$ \\
Constant & -0.6763 & 0.224 & - & - \\
\hline RC, regression coefficient & & &
\end{tabular}




\section{Conclusions}

The results of this study showed that the WC is significantly associated to hypercholesterolemia in the older population, suggesting that the WC measure, categorized in $\geq 90 \mathrm{~cm}$ for men and $\geq 80 \mathrm{~cm}$ for women, could be used as a tool for health surveillance when the goal is to identify older people more prone to hypercholesterolemia.

\section{References}

1. NCEP Expert Panel. Third Report of National Cholesterol Education Program (NCER) Expert Panel on detection, evaluation, and treatment of high blood cholesterol in adults (Adult Treatment Panel III). Final Report. Circulation 2002;106:3143-421.

2. Farzadfar F, Finucane MM, Danaei G, et al. National, regional, and global trends in serum total cholesterol since 1980: systematic analysis of health examination surveys and epidemiological studies with 321 country-years and $3 \cdot 0$ million participants. Lancet 2011;377:578-86.

3. Raposo L. Hipercolesterolemia familiar e Doença coronária prematura. Rev Factores Risco 2010;18:28-34.

4. Trapani L, Pallottini V, Trapani L, Pallottini V. Age-Related Hypercholesterolemia and HMG-CoA Reductase Dysregulation: Sex Does Matter (A Gender Perspective). Curr Gerontol Geriatr Res 2010;2010:1-7.

5. Hughes VA, Roubenoff R, Wood M, et al. Anthropometric assessment of 10-y changes in body composition in the elderly. Am J Clin Nutr 2004;80:475-82.

6. Rezende FAC, Rosado LEFPL, Ribeiro $\mathrm{R}$ de $\mathrm{CL}$, et al. Body mass index and waist circumference: association with cardiovascular risk factors. Arq Bras Cardiol 2006;87:728-34.

7. Karaouzene N, Merzouk H, Aribi M, et al. Effects of the association of aging and obesity on lipids, lipoproteins and oxidative stress biomarkers: A comparison of older with young men. Nutr Metab Cardiovasc Dis 2011;21:792-9.

8. Lee HH, Lee HJ, Cho JI, et al. Overall and abdominal adiposity and hypertriglyceridemia among Korean adults: the Korea National Health and Nutrition Examination Survey 2007-2008. Eur J Clin Nutr 2013;67:83-90.

9. WHO. Obesity: preventing and managing the global epidemic. Report of a WHO consultation. World Health Organ Tech Rep Ser 2000;894:1-253.

10. IBGE IB de G e E. Síntese de Indicadores Sociais: uma Análise das Condições de Vida. Rio de Janeiro: Instituto Brasileiro de Geografia e Estatística; 2010.

11. Albala C, Lebrão ML, León Díaz EM, et al. Encuesta Salud, Bienestar y Envejecimiento (SABE): metodología de la encuesta y perfil de la población estudiada. Rev Panam Salud Pública 2005; 17:307-22.

12. Coqueiro R da S, Santos MC, Neto J de SL, et al. Validity of a portable glucose, total cholesterol, and triglycerides multi-analyzer in adults. Biol Res Nurs 2014;16:288-94.
13. SBC SB de C. VI Diretrizes Brasileiras de Hipertensão Arterial. Rev Hipertens 2010;13:I-III.

14. Xavier HT, Izar MC, Faria Neto JR, et al. V Diretriz Brasileira de Dislipidemias e Prevenção da Aterosclerose. Arq Bras Cardiol 2013;101:01-22.

15. ABESO AB para o E da O e da SM. Diretrizes brasileiras de obesidade 2009/2010. Itapevi: Associação Brasileira para o Estudo da Obesidade e da Síndrome Metabólica; 2009.

16. Vasques ACJ, Priore SE, Rosado LEFP de L, Franceschini S do CC. Utilização de medidas antropométricas para a avaliação do acúmulo de gordura visceral. Rev Nutr 2010;23:107-18.

17. Rothberg AE, Halter JB. Obesity and Diabetes in an Aging Population. Clin Geriatr Med 2015;31:1-15.

18. Ribeiro Filho FF, Mariosa LS, Ferreira SRG, Zanella MT. Gordura visceral e síndrome metabólica: mais que uma simples associação. Arq Bras Endocrinol Metabol 2006;50:230-8.

19. Ross R. Advances in the application of imaging methods in applied and clinical physiology. Acta Diabetol 2003;40:S45-50.

20. Zahorska-Markiewicz B. Metabolic effects associated with adipose tissue distribution. Adv Med Sci 2006;51:111-4.

21. Nagatsuyu DT, Moriguti EKU, Pfrimer $\mathrm{K}$, et al. O impacto da obesidade abdominal sobre os níveis plasmáticos de lípides nos idosos. Medicina 2009;42:157. 